\title{
Rank-based poverty measures and poverty ordering with an application to Tunisia
}

\author{
Naouel Chtioui ${ }^{1}$ (D) \& Mohamed Ayadi $^{2}$
}

Received: 2 October 2016 / Accepted: 28 November 2017 /Published online: 6 January 2018 \# ISEG 2018

\begin{abstract}
Using the normative approach, we develop a class of poverty measures that is function of a weighting system. Each particular weighting function corresponds to a particular social judgment. This offers the decision-maker a large selection of social preferences functions, and he can choose the one that best represents his social judgment. We also develop new concepts of a-extended TIP curves. They are used to establish the conditions of the robust and unanimous poverty ranking of our measures. These conditions are in terms of second-and higher-degree TIP dominance. Finally, we provide an empirical illustration using Tunisian data on the 2005-2010 period.
\end{abstract}

Keywords SST Poverty ordering $\cdot$ Yaari dual social welfare function · TIP dominance

JEL Classification $\mathrm{C} 02 \cdot \mathrm{D} 63 \cdot \mathrm{D} 71 \cdot \mathrm{I} 31 \cdot \mathrm{I} 32$

* Naouel Chtioui

naouel.chtioui@gmail.com

Mohamed Ayadi

med.ayadi@gnet.tn

1 Département d'Informatique de l'Institut Supérieur des Langues Appliquées et d'Informatique de Béja, Université de Jendouba et UAQUAP, BP 340, Béja 9000, Tunisia

2 Département d'Economie et Méthodes Quantitatives, Institut Supérieur de Gestion et UAQUAP, Université de Tunis, I.S.G, 41 Cité Bouchoucha, 2000 Le Bardo, Tunisia 